\title{
Effect of cold storage on the biological fitness of Encarsia sophia (Hymenoptera: Aphelinidae), a parasitoid of Bemisia tabaci (Hemiptera: Aleyrodidae)
}

\author{
DAWIT KIDANE ${ }^{1,2}$, NiAN-WAN YANG $^{1, *}$ and FANG-HAO WAN ${ }^{1, *}$ \\ ${ }^{1}$ State Key Laboratory for Biology of Plant Disease and Insect Pests, Institute of Plant Protection, Chinese Academy of Agricultural \\ Sciences, Beijing, China; e-mails: dawitom14@yahoo.com; yangnianwan@caas.cn; wanfanghao@caas.cn \\ ${ }^{2}$ Department of Biology, College of Natural and Computational Sciences, Mekelle University, Tigray, Ethiopia
}

Key words. Hymenoptera, Aphelinidae, Encarsia sophia, storage at low temperature, fitness trait, emergence, longevity, parasitism rate, Hemiptera, Aleyrodidae, Bemisia tabaci

\begin{abstract}
Encarsia sophia (Girault \& Dodd) (Hymenoptera: Aphelinidae) is an important bio-control agent of Bemisia tabaci (Gennadius) (Hemiptera: Aleyrodidae). Storage at low temperature is a valuable method used in the mass rearing of biological control agents to ensure the availability of sufficient parasitoids when needed. However, storing parasitoids at a low temperature may lead to a decrease in their fitness. The aim of this study was to determine the effect of different durations of constant low temperature storage on the fitness traits of the above parasitoid. The effect of storage at three temperatures $\left(4,8\right.$ and $12 \pm 1{ }^{\circ} \mathrm{C}, \mathrm{RH}=65-75 \%$ and in darkness $)$ for periods of 1,2 or 3 weeks and at two pupal stages ( 10 and 12 days old) was studied. The percentage emergence, time to emergence, longevity, size and ability of the females that emerged to parasitize $B$. tabaci were evaluated. The results indicate that there is a decrease in percentage emergence, longevity and ability to parasitize the longer and lower the temperature at which the pupae of E. sophia are stored. The percentage emergence of both pupal stages kept at $12^{\circ} \mathrm{C}$ for a week was not affected. However, at lower temperatures $(8$ and $4^{\circ} \mathrm{C}$ ) percentage emergence after storage of two weeks decreased to $67-87.5 \%$ and after three weeks none emerged. The time to adult emergence was longer for 12 day old pupae at all temperatures and storage times. The longevity of the adults that emerged from both pupal stages after one week of storage at 12 and $8^{\circ} \mathrm{C}$ was not affected, but decreased to $66-72 \%$ with increase in storage time. There was no effect of cold storage on adult size when 10 day old pupae were stored. The ability of this parasitoid to parasitize $B$. tabaci after emerging from both pupal stages stored at all of the temperatures regardless of storage time was significantly lower. Effect of storage at $12^{\circ} \mathrm{C}$ for a week in terms of percentage emergence and longevity did not differ from that of the control, but nevertheless they were less able to parasitize B. tabaci. Although the information on the effect of cold storage on E. sophia is very limited, the results of this study indicate that for more efficient biological control there is an urgent need to improve the method of storing pupae.
\end{abstract}

\section{INTRODUCTION}

The silver leaf whitefly, Bemisia tabaci (Gennadius) (Hemiptera: Aleyrodidae) biotype B also called Middle East-Asia Minor1 (MEAM1) is recognized to be an important pest with high potential for spreading in China (Wan et al., 2005, 2009). An extensive survey conducted in China indicates that MEAM1 is present and rapidly becoming established in this country (Teng et al., 2010; Guo et al., 2012). The control of $B$. tabaci mainly depends on chemical insecticides, which have caused many serious problems (Ren et al., 2001) and several studies in this country indicate this pest has developed resistance to both conventional and new insecticides (He et al., 2007; Wang et al., 2010). However, the difficulty of controlling this pest using conventional and newer insecticides (He et al., 2007; Liang et al., 2012; Zheng et al., 2012), the increasing costs of chemical control and growing awareness of the risks to consumers of pesticide residues in fresh vegetables have resulted in a strong demand for non-chemical control methods in China (Yang et al., 2014). Li et al. (2011), record twentyseven species of parasitoids as the main natural enemies of B. tabaci and Trialeurodes vaporariorum in this country, all of which belong to the Aphelinidae, 21 in the genus Encarsia and 6 in Eretmocerus. Encarsia sophia (Girault \& Dodd) (Hymenoptera: Aphelinidae) is one of the important natural enemies of whiteflies in greenhouses (Goolsby et al., 1998; Giorgini \& Baldanza, 2004; Li et al., 2011) and is an effective biological control agent of B. tabaci (Zang \& Liu, 2008).

Encarsia sophia is an arrhenotokous autoparasitoid, which lays female eggs in whitefly nymphs and male eggs externally on female larvae of their own or of other parasitoid species (Hunter \& Kelly, 1998). E. sophia can kill whiteflies by parasitizing or feeding on them (Zang et al., 2011). Because of the promising results achieved, E. sophia is considered to be an important natural enemy of whiteflies. In order to more effectively use E. sophia in biological control programs it is important to know how tolerant it is of being stored at low temperatures as by developing effective means of storing them without affecting their fitness is a vital step in the mass production process. Cold storage is important in the mass rearing of biological control agents not only because it ensures the availability of sufficient numbers of natural enemies when they are needed (Lopez \& Botto, 2005; Silva et al., 2013), but also,

\footnotetext{
* Corresponding authors.
} 
as an important means of extending the shelf life of natural enemies (Colinet \& Boivin, 2011) and thereby increasing the flexibility and efficiency of mass rearing so that field releases of the natural enemies can be synchronized with the critical stages of pest outbreaks (Tezz \& Botto, 2004) and so reduce the cost of biological control by spreading the production period (Colinet \& Boivin, 2011).

Parasitoids are usually stored under sub-optimal low temperatures ranging from 0 to $15^{\circ} \mathrm{C}$ (Colinet \& Boivin, 2011) and this may lead to chilling injury, which determines the shelf life of insects (Lee, 2010). The cold induced extension of the shelf life of insects is associated with major fitness costs (Colinet et al., 2006; Ismail et al., 2010) in terms of reproductive success (van Baaren et al., 2005), foraging behaviour (van Baaren et al., 2006), sex ratio (Moiroux et al., 2014), mortality (Rundle et al., 2004; Bayram et al., 2005), mobility and flight capacity (Tezze \& Botto, 2004), longevity (Jalali \& Singh, 1992; Pandey \& Johnson, 2005) and fecundity (Levie et al., 2005). Temperature is one of the main factors affecting survival during cold storage. Generally storage at a lower temperature results in a higher mortality. However, Al-Tememi \& Ashfaq (2005) report that temperature had no effect on the survival of Bracon hebetor. Several previous studies indicate that survival of parasitoids decreases with increase in the period for which they are stored (Bayram et al., 2005; Lopez \& Botto, 2005; Colinet et al., 2006; Ayvaz et al., 2008; Colinet \& Hance, 2010). In addition to temperature, duration of exposure is also an important factor determining the survival of parasitoids. The interaction of these two factors determines the percentage mortality of the parasitoid. However, considering that species show different responses to low-temperature, the possibility of differences in cold induced mortality associated with geographical origin should not be ignored.

The pupal stage is often considered to be the most suitable for short-term storage. Jalali \& Singh (1992) and Nakama \& Foerster (2001), show that pupae are more cold tolerant than eggs, larvae or adults. In addition, this stage is immobile and easier to handle, and within-life-stage effects may also contribute to the variation in the effect of cold storage (Bowler \& Terblanche, 2008). Another study by Colinet et al. (2013) indicates a clear within-stage variation in cold tolerance. Here again, variability in tolerance of pupae to cold storage depends on the species. Foerster et al. (2004) suggest that parasitoids that are stored as young pupae spend more energy completing their development, which in turn had a negative effect on percentage emergence and longevity. In contrast, this does not occur when young and old Aphidius rhopalosiphi pupa are stored (Levie et al., 2005). There is little knowledge on the tolerance of pupal stages to low temperatures. It is evident that there are age-related variations in the tolerance of a particular stage to cold storage, therefore, it is important to determine which developmental stage is the most suitable for keeping in cold storage.

Each species of parasitoid differs in its adaptability. Several studies indicate that there are large interspecific differences in tolerance to cold storage even between closely related sibling species (Lopez \& Botto, 2005; Colinet \& Hance, 2010; Spinola-Filho et al., 2014). Most cold storage studies indicate that parasitoids differ in their tolerance of cold storage and therefore it is necessary to determine the tolerance of cold storage of each parasitoid prior to its use in biological control (Foerster et al., 2004; Tezz \& Botto, 2004; Bayram et al., 2005). There is no general guideline to follow because of the differences between species in their tolerance of low temperatures. Thus, there is a need to determine the tolerance of cold storage of species of parasitoid, such as, E. sophia. The available literature on the tolerance of cold storage of the genus Encarsia is mainly for E. formosa because of its wide use for controlling whiteflies. To date, no study has been undertaken to investigate the effect of cold storage on the fitness of E. sophia.

Therefore, the aim of this study is to determine the effect of low temperature storage on some of the biological parameters of E. sophia. In particular, the hypothesis that the quality of the parasitoid decreases with increase in the period for which it is kept in storage and with decrease in storage temperature. Whether the negative effects of exposure to cold conditions affect the pupal stages differently is also examined. The effect of storage was evaluated in terms of percentage emergence, time to emergence, size, longevity and ability to parasitize $B$. tabaci.

\section{MATERIAL AND METHODS}

\section{Stock cultures of insects}

The stock culture of B. tabaci MEAM1 used in this experiment was previously maintained in a rearing room for four years without any exposure to pesticides at Langfang Experiment Station $\left(39^{\circ} 30^{\prime} \mathrm{N}, 116^{\circ} 36^{\prime} \mathrm{E}\right)$, Institute of Plant Protection, Chinese Academy of Agricultural Sciences (CAAS). The laboratory colony of E. sophia was established from parasitized B. tabaci populations maintained on melon plants in a greenhouse at the Vegetable IPM Laboratory, Texas Agricultural Experiment Station at Weslaco, TX, USA, in 2008. The whiteflies were reared in a room kept at $26 \pm 1{ }^{\circ} \mathrm{C}, 50 \pm 10 \% \mathrm{RH}$ and under a photoperiod of $14 \mathrm{~L}$ : 10D. Cotton Gossypium hirsutum L. Zhong-Mian 8 variety was used as a host plant for rearing the whitefly. The parasitoid, $E$. sophia, was reared separately on whiteflies kept under the same controlled conditions as stated above for whitefly.

\section{Pupae used for determining tolerance of cold storage}

Cold storage experiments were carried out on the pupal stages of E. sophia. To obtain parasitoid pupae, cotton plants infested with high numbers of third instar nymphs of $B$. tabaci were exposed to the parasitoid for $48 \mathrm{~h}$ in a parasitoid rearing cage. Parasitoids at two different pupal stages, 12 and 10 days old, respectively, were carefully collected from the leaves of the cotton plants and randomly assigned to each of the following storage temperature treatments. Precautions were taken to avoid overlap of the pupal stages by removing those pupae that did not change colour on the 9th day and keep those that did for the experiment. Ten parasitized hosts at each pupal stage were placed in a vial (1.5 $\mathrm{cm}$ diameter and $3 \mathrm{~cm}$ long) closed with cotton wool and transferred to 4 different climatic chambers (Saife Instruments, PRX$450 \mathrm{D}-30,0-50 \pm 1{ }^{\circ} \mathrm{C}, 50-90 \% \pm 5 \% \mathrm{RH}$ ) each set at either 4,8 or $12 \pm 1{ }^{\circ} \mathrm{C}$, where they were kept under dark conditions for 1,2 or 3 weeks at $75 \pm 5 \%$ R.H. There were 10 replicates of each treatment and random allocation to the storage treatments. On completion of each of the storage treatments the pupae were transferred to 
standard conditions of $26 \pm 1{ }^{\circ} \mathrm{C}, 65 \pm 5 \%$ R.H. and a $14 \mathrm{~L}: 10 \mathrm{D}$ photoperiod. The control pupae were kept under standard conditions in a bioclimatic chamber. For all the treatments, the effect of storage on performance of the parasitoids was evaluated by measuring the following: percentage emergence, time to emergence, longevity, size and ability to parasitize $B$. tabaci.

\section{Percentage emergence and time to emergence}

The percentage emergence was measured by checking the number of adults that emerged once a day at the same time. The percentage adult emergence was calculated based on the number of individuals that emerged from all the pupae.

The time to adult emergence was calculated from the end of each cold treatment and return to standard conditions to the day of emergence. For the control treatment, the emergence time was calculated from the day the pupae were stored under standard conditions to the day of emergence. Emergence was checked at the same time each day. Percentage of adults that emerged over time was calculated by dividing the number of adults that emerged each day by the total number of adults that emerged in each treatment.

\section{Longevity}

The longevity of the adult parasitoids was evaluated as follows. Thirty adults less than $24 \mathrm{~h}$ old from each treatment were kept individually in small vials $(1.5 \times 3 \mathrm{~cm})$. The vials were kept at $26 \pm 1{ }^{\circ} \mathrm{C}, 65 \pm 5 \%$ R.H. and a $14 \mathrm{~L}: 10 \mathrm{D}$. A drop of honey and water was provided daily until the wasp died. Due to the reduced emergence from 12 day old pupae kept at $4^{\circ} \mathrm{C}$ for 1 and 2 weeks and from 10 day old pupae kept at either 4,8 or $12^{\circ} \mathrm{C}$ for 2 weeks, a lower number of 12-25 individuals were used. The longevity in days was measured by recording deaths at the same time each day.

\section{Size}

The size of the adults was evaluated by measuring the hind tibia. The length of the hind tibia is frequently used as a proxy for adult size. The length of the hind tibia was measured using an ocular micrometer mounted on a compound microscope (Olympus, SZX-ILLD2-200) at a magnification of $90 \times$

\section{Parasitism (\%)}

The \% parasitism of B. tabaci was evaluated as follows. Ten females of E. sophia less than 24 h old were randomly selected from each treatment (including control) and placed in a vial with a male for $20 \mathrm{~min}$. As no males emerged from the pupae used in the different treatments, males that had not been exposed to any of the treatments were used. After mating, each female was offered $403^{\text {rd }}$ to $4^{\text {th }}$ instar nymphs of $B$. tabaci in a Petri dish containing a cotton leaf disc on a $1 \%$ agar solution covered by a plastic film for $48 \mathrm{~h}$. After $48 \mathrm{~h}$ the females were removed and the
Petri dishes were kept in a climatic chamber at $26 \pm 1{ }^{\circ} \mathrm{C}, 65 \pm 5 \%$ RH and 14L : 10D. After 8 to 12 days the number of parasitized pupae produced per female was recorded. To maintain the humidity the vials were kept in larger rectangular plastic boxes $(18 \mathrm{~cm}$ long $\times 12 \mathrm{~cm}$ wide $\times 6 \mathrm{~cm}$ deep) containing wet filter paper.

\section{Statistical analysis}

The differences in the mean \% emergence, longevity and size of the adult E. sophia were analyzed using one-way ANOVA with the storage temperature and storage period combinations as factors. Differences among the means related to different treatments were compared using Tukey's Honestly Significant Difference (HSD) test and a significance level of $\mathrm{p}=0.05$. A two-way ANOVA was used, with storage temperature and storage time as factors, to analyze their effects on the percentage emergence of adults.

As percentage parasitism of the $B$. tabaci offered to the adults that emerged from 12 day old pupae did not meet the assumptions for homoscedasticity, these values were analyzed using a Kruskal-Wallis test. Multiple comparisons after the KruskalWallis test were performed using the Dunnett T3 test. The results for percentage parasitism of adults that emerged from 10 day old pupae were analyzed using a one way ANOVA as they fulfill the normality and homogeneity criteria. Treatment differences were considered significant at $P<0.05$.

Since the results for the time to emergence from both pupal stages do not meet the homoscedasticity and normality criteria, a generalized linear model based on a gamma distribution and loglink function was used. The analyses were carried out using SPSS version 21 software package.

\section{RESULTS}

\section{Percentage emergence}

The percentage emergence of E. sophia was significantly affected by both the storage temperature and storage period (Table 1). There were significant interactions between storage temperature and storage period on percentage emergence from the two pupal stages (Table 1).

No adults emerged from both pupal stages kept in cold storage for 2 weeks. The \% emergence of E. sophia from 10 day old pupae was 90,73 and 26 , respectively, for the pupae stored at 12,8 and $4^{\circ} \mathrm{C}$ for a week. For 10 day old pupae, the percentage emergence of adults after 1 and 2 weeks of cold storage was significantly lower than that recorded for the control $\left(F_{6,63}=158.16, P<0.0001\right)$, except for those stored at $12^{\circ} \mathrm{C}$ for 1 week (Table 2). For 12 day old pupae the $\%$ emergence was 79,78 and 36 , respec-

TABLE 1. The results of ANOVA of the effect of storage period and storage temperature on the percentage of E. sophia that emerged from pupae of different ages (Tukey's HSD test).

\begin{tabular}{lrrrr}
\hline \multicolumn{1}{c}{ Source } & $d f$ & Mean Square & \multicolumn{1}{c}{$F$} & $P$ \\
\hline 10 day old pupae & & & & $<0.0001$ \\
$\quad$ Storage period & 1 & 26041.667 & 383.174 & $<0.0001$ \\
Storage temperature & 2 & 12301.667 & 181.005 & $<0.0001$ \\
Storage period $\times$ storage temperature & 2 & 2051.667 & 30.188 & \\
Error & 54 & 67.963 & & $<0.0001$ \\
$\quad$ Total & 60 & & & \\
\hline 12 day old pupae & 1 & 10666.667 & 119.502 & 0.0001 \\
$\quad$ Storage period & 2 & 11180.000 & 125.253 & \\
Storage temperature & 2 & 346.667 & 3.884 & \\
Storage period $\times$ storage temperature & 54 & 89.259 & & \\
Error & 60 & & & \\
Total & & & & \\
\hline
\end{tabular}


TABLE 2. Percentage emergence of E. sophia from pupae stored at different ages for two periods at different temperatures (mean $\pm \mathrm{SE}$ ).

\begin{tabular}{lcc}
\hline \multirow{2}{*}{ Storage treatment } & \multicolumn{2}{c}{ Precentage emergence after storage $(\%)^{\mathrm{a}}$} \\
\cline { 2 - 3 } & 10 day old pupae & 12 day old pupae \\
\hline Control & $88.0 \pm 3.6 \mathrm{aA}$ & $90.0 \pm 2.6 \mathrm{aA}$ \\
$12^{\circ} \mathrm{C}-1$ week & $90.0 \pm 3.3 \mathrm{aA}$ & $79.0 \pm 3.1 \mathrm{aB}$ \\
$12^{\circ} \mathrm{C}-2$ weeks & $42.0 \pm 2.0 \mathrm{cA}$ & $43.0 \pm 3.4 \mathrm{cA}$ \\
$8^{\circ} \mathrm{C}-1$ week & $73.0 \pm 2.6 \mathrm{bA}$ & $78.0 \pm 5.0 \mathrm{aA}$ \\
$8^{\circ} \mathrm{C}-2$ weeks & $15.0 \pm 2.7 \mathrm{deB}$ & $58.0 \pm 2.5 \mathrm{bA}$ \\
$4^{\circ} \mathrm{C}-1$ week & $26.0 \pm 2.2 \mathrm{~dB}$ & $36.0 \pm 2.2 \mathrm{cA}$ \\
$4^{\circ} \mathrm{C}-2$ weeks & $7.0 \pm 2.6 \mathrm{eA}$ & $12.0 \pm 2.9 \mathrm{dA}$ \\
\hline
\end{tabular}

${ }^{a}$ Means followed by different lower case letters within the same column were significantly different (Turkey's HSD test at $\mathrm{p}<$ 0.05 ); means followed by different upper case letter within the same row were significantly different (Independent $\mathrm{T}$ test at $\mathrm{p}<$ $0.05)$.

tively, for pupae stored at 12,8 and $4{ }^{\circ} \mathrm{C}$ for a week. The percentage emergence of adults after cold storage for 1 and 2 week were significantly lower than that recorded for the controls $\left(F_{6,63}=77.929 P<0.0001\right)$, except for those stored at $12^{\circ} \mathrm{C}$ and $8^{\circ} \mathrm{C}$ for 1 week (Table 2). The percentage emergence of adults from both pupal stages decreased with decrease in storage temperature and increase in the storage period.

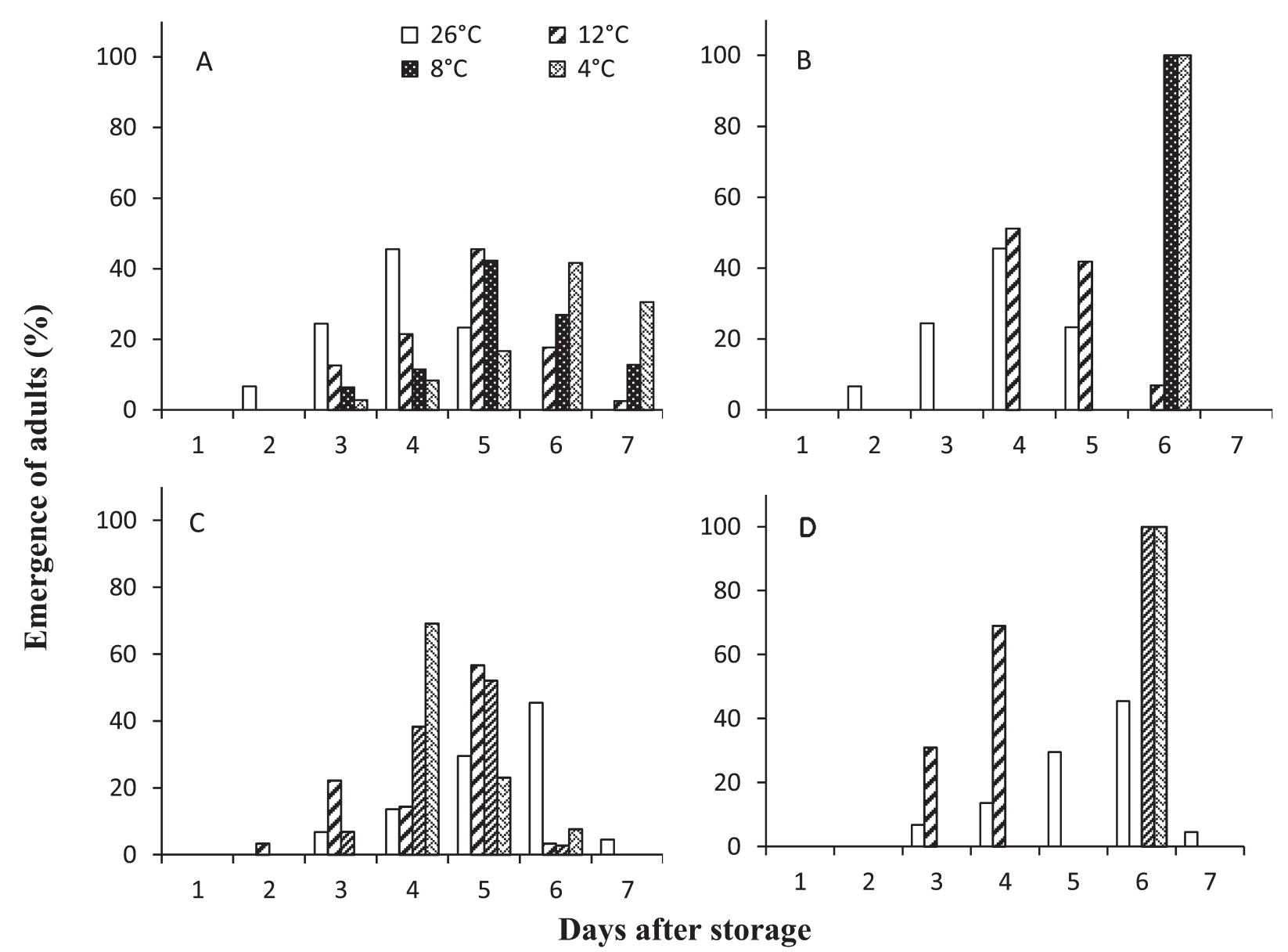

Fig. 1. Percentage of E. sophia that emerged over time from pupae that were stored at two different stages of development and subjected to one of four treatments: (A) 12 day old pupae after storage for 1 week, (B) 12 day old pupae after storage for 2 weeks, (C) 10 day old pupae after storage for 1 week and (D) 10 day old pupae after storage for 2 weeks.

The percentage emergence of adults from 12 day old pupae was significantly higher than from 10 day old pupae stored at $8^{\circ} \mathrm{C}$ for 2 weeks and $4^{\circ} \mathrm{C}$ for 1 week $[\mathrm{t}(18)=$ $-3.20, \mathrm{p}=0.005]$; whereas percentage emergence from 10 day old pupae stored at $12^{\circ} \mathrm{C}$ for 1 week was significantly higher $[\mathrm{t}(18)=-11.73, \mathrm{p}<0.0001]$. The results for 10 and 12 day old pupae in the other three storage treatments did not differ significantly (Table 2 ).

In the control treatment $\left(26^{\circ} \mathrm{C}\right)$ the percentage of adults that emerged from both 12 and 10 day old pupae was greater than $85 \%$ and the percentage emergence of those stored for a week at 12 and $8^{\circ} \mathrm{C}$ was greater than $70 \%$ (Table 2). However, a storage period longer than a week negatively affected the mean percentage emergence of adults when compared with the control (Table 2).

\section{Time to adult emergence}

In the control treatment, adults started to emerge from 12 day old pupae after 2 days and continued to do so for up to 4 days with the greatest percentage emerging on day 4 and from 10 day old pupae after 3 days with the greatest percentage emerging on day 6 (Fig. 1). The average time to emergence for 12 and 10 day old pupae was $3.9 \pm 0.1$ and $5.3 \pm 0.1$ days, respectively (Fig. 2).

The period over which adults emerged from both 12 and 10 day old pupae after cold storage for one week was $4 \sim 5$ 
A

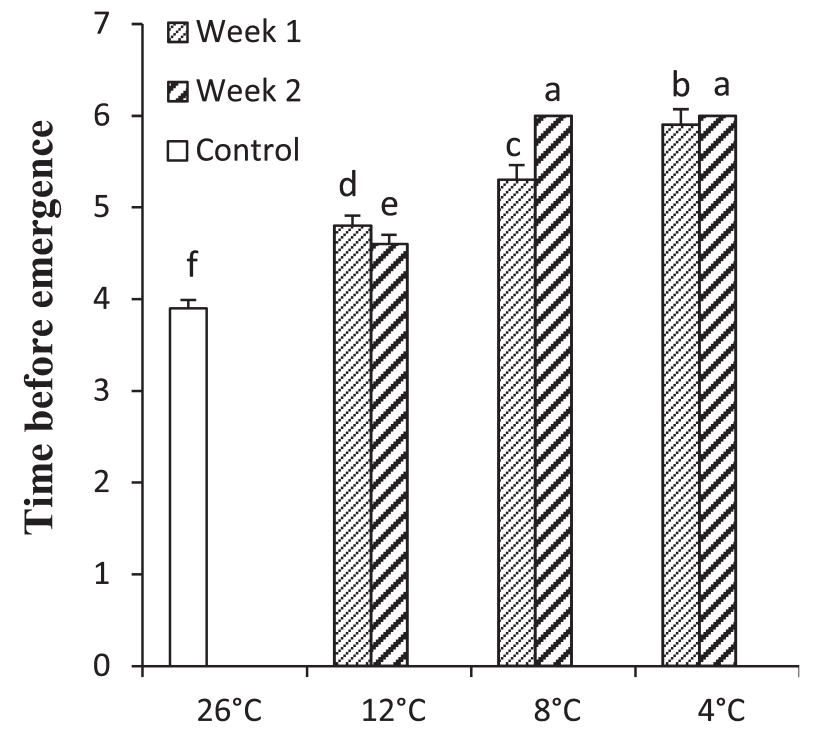

B

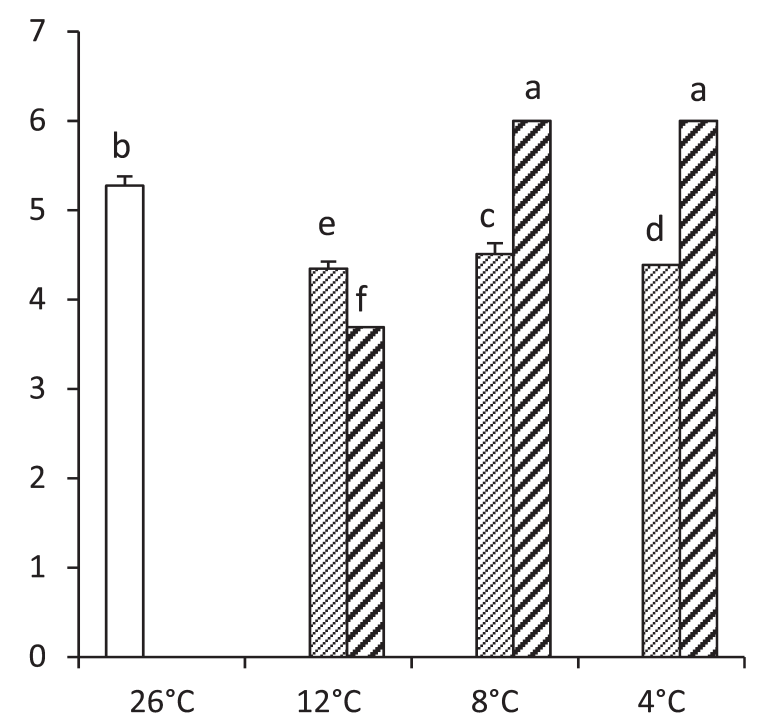

\section{Cold storage treatment}

Fig. 2. Mean time ( \pm SE) to adult emergence after storage (days) of pupae of E. sophia at different temperatures. (A) 12 day old pupae and (B) 10 day old pupae. Columns topped by different letters are significantly different (Dunnett T3 test; P $<0.05$ ) in the time to emergence among the different storage temperatures.

days (Fig. 1A, C). However, the adults began to emerge on day 3 and the greatest percentage emerged on days $1 \sim 2$ in the control. Adults began emerging from 10 day old pupa on day 2, 3 and 4, respectively, after storage at 12, 8 and $4^{\circ} \mathrm{C}$ for one week, with greatest percentage of adults emerging 1 2 days earlier than recorded for the control, which is the opposite to that recorded for 12 day old pupae (Fig. 1A, C). The average time to emergence from 12 day old pupae was significantly longer than that recorded for the control and the lower the storage temperature the longer the time to emergence (Fig. 2). For 10 day old pupae, the average time to emergence was around 4 days for all of the three cold storage temperatures, which is 1 day shorter than that recorded for the control (Fig. 2).

The emergence of adults after cold storage of pupae for 2 weeks lasted for 1 4 days for both 12 and 10 day old pupae (Fig. 1B, D). However, the adults began to emerge from 12 day old pupae after 2 weeks of storage at all of the three

TABLE 3. Multiple comparisons of the mean time to emergence of $E$. sophia from pupae of different ages kept in cold storage for different periods and at different temperatures. Scale parameters estimated based on maximum likelihood. Different letters in a column indicate a significant difference $(\alpha=0.05)$.

\begin{tabular}{ccc}
\hline & 10 day old & 12 day old \\
\hline Storage time (weeks) & $\mathrm{a}$ & $\mathrm{b}$ \\
0 & $\mathrm{~b}$ & $\mathrm{a}$ \\
1 & $\mathrm{~b}$ & $\mathrm{a}$ \\
2 & & \\
Storage temperature $\left({ }^{\circ} \mathrm{C}\right)$ & $\mathrm{a}$ & $\mathrm{c}$ \\
26 & $\mathrm{c}$ & $\mathrm{b}$ \\
12 & $\mathrm{~b}$ & $\mathrm{a}$ \\
8 & $\mathrm{~b}$ & $\mathrm{a}$ \\
4 & &
\end{tabular}

temperatures on day 4 with the greatest percentage emerging on days $1 \sim 2$ as in the controls. Adults began to emerge from pupae stored at $12^{\circ} \mathrm{C}$ on day 4 and those stored at 8 and $4^{\circ} \mathrm{C}$ on day 6 with the greatest percentage recorded $2 \sim 4$ days later than that recorded for the control. The average time to emergence from 12 day old pupae was significantly longer than recorded for the control and those stored at the lowest temperature took even longer to emerge and the adults all emerged on the same day (Fig. 2). For 10 day old pupae, the average time to emergence was around 4 days when the pupae were stored at $12^{\circ} \mathrm{C}$ and 6 days when stored at 8 and $4^{\circ} \mathrm{C}$, which is 1 day shorter at $12^{\circ} \mathrm{C}$ and 1 day longer at 8 and $4^{\circ} \mathrm{C}$ than that recorded for the control. The emergence of adults from pupae stored at lower temperatures occurs simultaneously 6 days after the 12 and 10 day old pupae were transferred to normal temperature conditions (Figs 1 and 2).

The time required for adults to emerge after cold storage of both pupal stages depended on the storage temperature (Fig. 2A and B). The time to emergence from 10 day and 12 day old pupae after one week of cold storage in all treatments was shorter than that recorded for the control. Whereas after storage for two weeks at 8 and $4{ }^{\circ} \mathrm{C}$ the time to emergence was 6 days, which is longer than the 5.2 days recorded for the control (Fig. 2B). The time to emergence was significantly affected by the duration of cold storage $\left(\chi^{2}=106.171, P<0.001\right)$ and the temperature at which they were stored $\left(\chi^{2}=257.930, P<0.001\right)$. Multiple comparisons (Table 3 ) indicate that the time to adult emergence recorded for the control is longer than recorded for pupae stored at low temperatures for 1 and 2 weeks. In contrast, the time to emergence from 12 day old pupae in all storage treatments was longer than for the control. The time to emergence was significantly affected by the duration of 
A

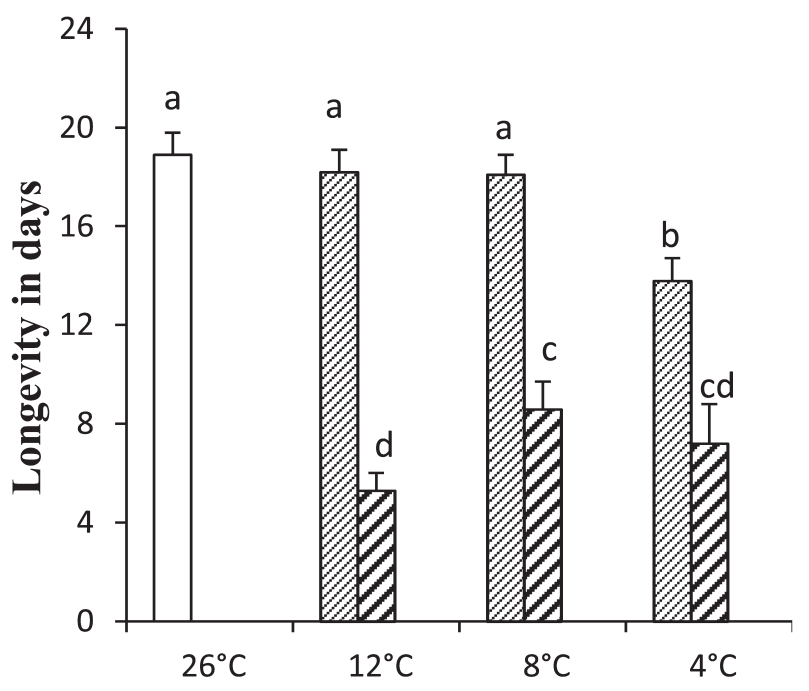

B

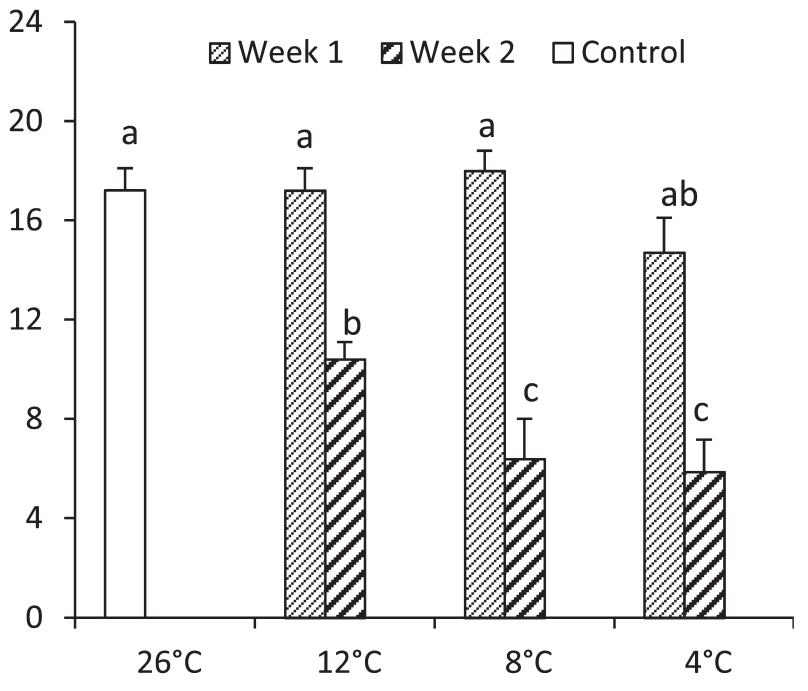

Cold storage treatment

Fig. 3. Mean $( \pm \mathrm{SE})$ longevity of adults of E. sophia that emerged from pupae stored at different developmental stages, different temperatures and for different periods. (A) 12 day old pupae and (B) 10 day old pupae. Columns topped by different letters are significantly different (Tukey HSD test, $\mathrm{P}<0.05$ ).

cold storage $\left(\chi^{2}=287.186, P<0.001\right)$ and the temperature at which they were stored $\left(\chi^{2}=330.448, P<0.001\right)$. There was a significant interaction between the temperature and the period for which the pupal stages were stored (Table 3; $\chi^{2}=283.121, P<0.001$ for 10 -d old pupa and $\chi^{2}=386.911$, $P<0.001$ for 12 -d old pupa).

\section{Longevity}

The longevity of E. sophia was significantly affected by both the temperature and the period for which the pupae were stored (Table 4). There was a significant interaction between the temperature and the period for which the pupae were stored (Table 4).

The longevity of adults that emerged from 10 day old pupae stored at 12,8 and $4{ }^{\circ} \mathrm{C}$ for a week were 17,18 and 15 days, respectively. After two weeks of storage it declined to $10 \sim 6$ days. The longevity of adult E. sophia after cold storage of pupae for 2 weeks is significantly shorter than that recorded for the control (Fig. 3B; $F_{6,177}=36.675, P$ $<0.0001)$. The longevity of adults that emerged from 12 day old pupae stored at 12 and $8^{\circ} \mathrm{C}$ for a week was 18 days and from pupae stored at $4^{\circ} \mathrm{C}$ for one week was 14 days. After two weeks of storage longevity was 9 5 days. The longevity of E. sophia after cold storage of pupae for 1 and 2 weeks is significantly shorter than that recorded for the control (Fig. 3A; $F_{6,150}=17.42, P<0.0001$ ), except for those stored at 12 and $8^{\circ} \mathrm{C}$ for 1 week.

\section{Size}

The two-way ANOVA revealed no significant effect of the period and temperature at which the pupae were stored or the storage period $\times$ storage temperature on the size of the adults that emerged from 10 day old pupae (Table 5). While for 12 day old pupae storage period had a significant effect on the size of the adults, the storage temperature or storage period $\mathrm{x}$ storage temperature did not.

For 10 day old pupae there is no significant difference in size of the adults that emerged in the control $(151.8 \pm 2.2$ $\mu \mathrm{m})$ and other treatments (ranged 136.5 $\pm 5.8-149.7 \pm 2.8$ $\mu \mathrm{m})$ and all storage periods $\left(F_{6,151}=1.503, P=0.181\right)$. For 12 day old pupae, the parasitoids that emerged in all the temperature treatments (ranged from 142.4 $\pm 2.4 \sim 150.6 \pm$

TABLE 4. The results of ANOVA of the effect of the storage period and storage temperature on the longevity of E. sophia that emerged from the pupae stored under the conditions detailed below (Tukey's HSD test).

\begin{tabular}{|c|c|c|c|c|}
\hline Source & $d f$ & Mean Square & $F$ & $P$ \\
\hline $\begin{array}{l}10 \text { day old pupae } \\
\text { Storage period } \\
\text { Storage temperature } \\
\text { Storage period } \times \text { storage temperature } \\
\text { Error } \\
\text { Total } \\
\end{array}$ & $\begin{array}{c}1 \\
2 \\
2 \\
121 \\
127 \\
\end{array}$ & $\begin{array}{l}3.293 \\
0.305 \\
0.173 \\
0.044\end{array}$ & $\begin{array}{r}74.492 \\
6.906 \\
3.903\end{array}$ & $\begin{array}{r}<0.0001 \\
<0.001 \\
0.023\end{array}$ \\
\hline $\begin{array}{l}12 \text { day old pupae } \\
\text { Storage period } \\
\text { Storage temperature } \\
\text { Storage period } \times \text { storage temperature } \\
\text { Error } \\
\text { Total }\end{array}$ & $\begin{array}{c}1 \\
2 \\
2 \\
148 \\
154\end{array}$ & $\begin{array}{r}3233.150 \\
92.468 \\
106.877 \\
23.589\end{array}$ & $\begin{array}{r}137.060 \\
3.920 \\
4.531\end{array}$ & $\begin{array}{r}<0.0001 \\
0.022 \\
0.012\end{array}$ \\
\hline
\end{tabular}




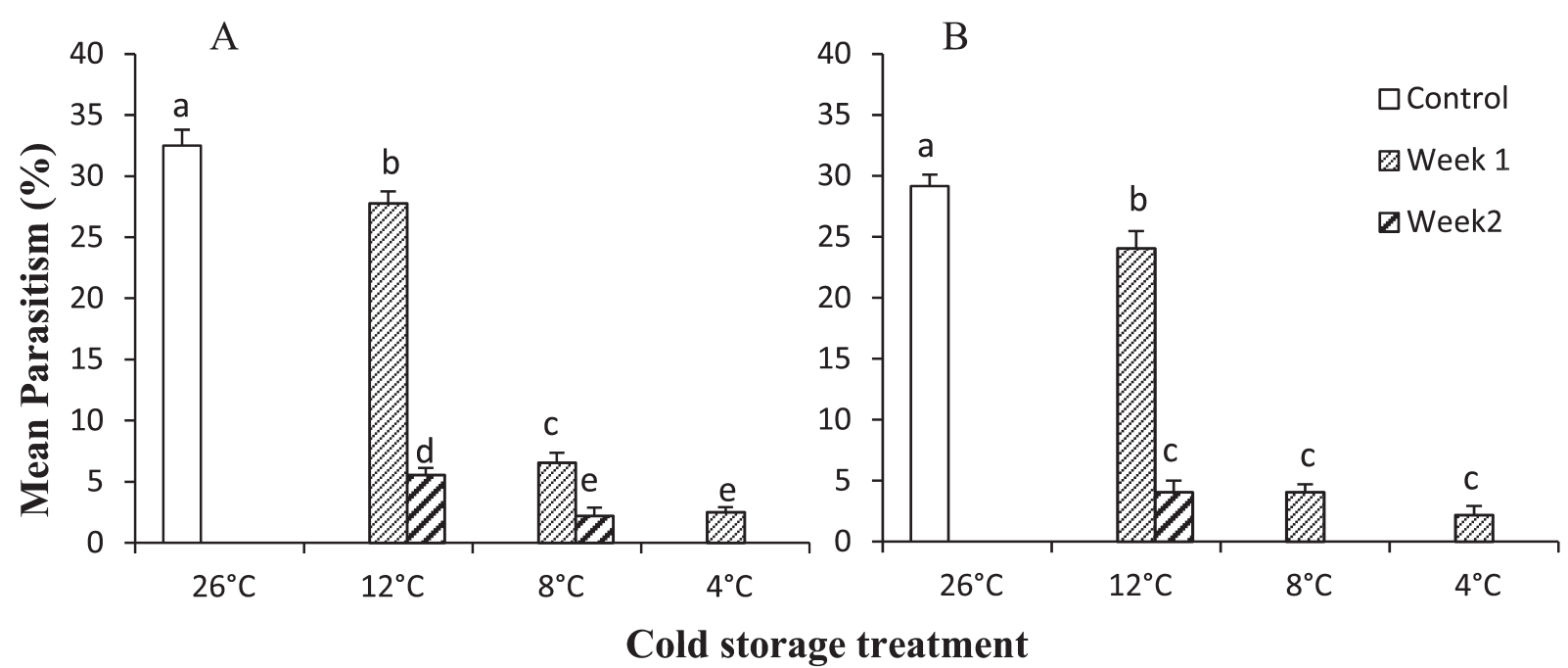

Fig. 4. Mean percentage of $B$. tabaci parasitized $( \pm \mathrm{SE})$ by E. sophia that emerged from pupae stored at different temperatures; (A) 12 day old pupae and (B) 10 day old pupae. Means topped by a different letters differ significantly (Dunnett T3 test; P $<0.05$ ).

$5.5 \mu \mathrm{m})$ were significantly smaller than that recorded for the control $\left(157.2 \pm 2.4 \mu \mathrm{m} ; F_{6,180}=4.917, P<0.001\right)$.

\section{Percentage of $B$. tabaci parasitized}

The percentage of B. tabaci parasitized by E. sophia that emerged from 12 day old pupae was significantly affected by the temperature and period for which they were stored. There was a significant interaction between storage temperature and storage period (Table 6).

The mean percentage parasitized by females that emerged from 10 day and 12 day old pupae that were stored at different temperatures is presented in Fig. 4. The percentage parasitized by adults that emerged from 12 day old pupae stored at 12,8 and $4^{\circ} \mathrm{C}$ for a week were $27.5,6.6$ and 2.5 percent, respectively. The percentage parasitized by females that emerged from 12 day old pupae stored at $12^{\circ} \mathrm{C}$ for a week was $14.5 \%$ less than that recorded for the control (Fig. 4A; $\chi^{2}=44.485, d f=5, P<0.001$ ) and after two weeks storage under these conditions it was $16.9 \%$ of that recorded for the control. Similarly, the 10 day old pupae also showed the same trend. The percentage parasitized by adults that emerged from 10 day old old pupae kept at 12,8 and $4^{\circ} \mathrm{C}$ for a week was $24.1,4.0$ and 2.2 , respectively. The percentage parasitized by females that emerged from pupae after 1 week of storage at $12^{\circ} \mathrm{C}$ was $82.5 \%$ of that recorded for the control (Fig. 4B; $F_{4,36}=179.406, P<$ $0.001)$. Percentage parasitized by E. sophia that emerged from both pupal stages sharply declined when they were stored below $12^{\circ} \mathrm{C}$, regardless of the time for which they were stored. Treatments that used 10 day old pupae stored at $8^{\circ} \mathrm{C}$ and $4^{\circ} \mathrm{C}$ and 12 day old pupa stored at $4^{\circ} \mathrm{C}$ for two weeks produced very few parasitoids and therefore these treatments were excluded.

\section{DISCUSSION}

The percentage emergence of E. sophia follows expected patterns: it decreases with increase in the time and deceases in the temperature at which the pupae are stored. However, the percentage emergence from both pupal stages stored at 12 and $8^{\circ} \mathrm{C}$ for 1 week were similar to that recorded in the control. After storing the pupae for two weeks the percentage emergence was reduced by $52-53 \%$ for both pupal stages even when stored at $12^{\circ} \mathrm{C}$. As reported in many other studies, exposure to prolonged cold storage has a negative effect on the emergence of parasitic wasps (Jalali \& Singh, 1992; Ganteaume et al., 1995b; Tezz \& Botto, 2004; Colinet \& Hance, 2010; Silva et al., 2013). The level of accumulated injury increases with increase in the duration of exposure (Kostal et al., 2006) and chilling injury accumulates and eventually becomes lethal. In the

TABLE 5. The result of ANOVA of the effect of storage period and storage temperature on the size of E. sophia that emerged from pupae stored under the conditions detailed below.

\begin{tabular}{|c|c|c|c|c|}
\hline Source & $d f$ & Mean Square & $F$ & $P$ \\
\hline $\begin{array}{l}10 \text { day old pupae } \\
\text { Storage period } \\
\text { Storage temperature } \\
\text { Storage period } \times \text { storage temperature } \\
\text { Error } \\
\text { Total } \\
\end{array}$ & $\begin{array}{r}1 \\
2 \\
2 \\
127 \\
133 \\
\end{array}$ & $\begin{array}{l}5.457 \\
1.306 \\
3.859 \\
1.966\end{array}$ & $\begin{array}{l}2.776 \\
0.664 \\
1.963\end{array}$ & $\begin{array}{l}0.098 \\
0.516 \\
0.145\end{array}$ \\
\hline $\begin{array}{l}12 \text { day old pupae } \\
\text { Storage period } \\
\text { Storage temperature } \\
\text { Storage period } \times \text { storage temperature } \\
\text { Error } \\
\text { Total } \\
\end{array}$ & $\begin{array}{r}1 \\
2 \\
2 \\
151 \\
157\end{array}$ & $\begin{array}{l}6.109 \\
0.142 \\
2.373 \\
1.248\end{array}$ & $\begin{array}{l}4.894 \\
0.114 \\
1.901\end{array}$ & $\begin{array}{l}0.028^{*} \\
0.893 \\
0.153\end{array}$ \\
\hline
\end{tabular}

\footnotetext{
$* \mathrm{P}<0.05$ (Tukey's HSD test).
} 
TABLE 6. The result of ANOVA of the effect of storage period and storage temperature on the ability of the adults of E. sophia that emerged from the pupae to parasitize B. tabaci (Tukey's HSD test).

\begin{tabular}{lcccc}
\hline Source & $d f$ & Mean Square & $F$ & $P$ \\
\hline 12 day old pupae & 1 & 246.307 & 353.052 & $<0.0001$ \\
Storage period & 2 & 211.643 & 303.366 & $<0.0001$ \\
Storage temperature & 1 & 111.627 & 160.004 & $<0.0001$ \\
Storage period $\times$ storage temperature & 39 & 0.698 & & \\
Error & 44 & & & \\
Total & & & \\
\hline
\end{tabular}

present study the effect on young pupal stages was relatively severe, probably because they have fewer energy reserves compared to late pupal stages. Hence survival at low temperatures is related to the depletion of energy reserves (Colinet et al., 2006) and parasitoids stored as young pupae need more energy to complete their development (Foerster et al., 2004).

A $70 \%$ reduction in emergence of $E$. formosa from pupae stored at $10^{\circ} \mathrm{C}$ for $41-50$ days is reported, by Scopes et al. (1973). However, the study carried out by Lopez \& Botto (2005) record a $90 \%$ emergence of E. formosa at $11.5^{\circ} \mathrm{C}$ after 28 days of storage. Ganteaume et al. (1995a) suggest the best percentage emergence of E. sophia occurs at $9^{\circ} \mathrm{C}$ after being kept for only 15 days. In this study the percentage emergence was not affected at 12 and $8^{\circ} \mathrm{C}$ after being kept for only a week. This difference may be due to the geographical origin of the species used in these studies.

No adults emerged from both pupal stages after 2 weeks of storage at all of the low temperatures used. Storage of pupae of E. sophia at cold temperatures has a negative effect on the percentage emergence of adults. The pre-experiment carried out during this study also resulted in no adults emerging when pupae were kept at $0^{\circ} \mathrm{C}$, which also indicates that $E$. sophia is not tolerant of low temperatures.

In order to synchronize the release of parasitoids at a critical stage in a pest outbreak it is vital to know not only when the adult parasitoids will emerge but also how many. The emergence of the adults was spread over five and three days for 12 and 10 day old pupae kept for one week in all temperature treatments, respectively, reaching maxima on the $5^{\text {th }}$ day after transferring from cold storage. The average development of 12 day old pupae was slower in all the temperature treatments compared to the control, being 1-2 days longer. On the other hand, 10 day old pupae kept for a week in all the temperature treatments were shorter compared to the control. This difference indicates variability in the physiological activity of the different pupal stages, which determines their cold tolerance. Studies carried out by Lysyk (2004) and Colinet \& Hance (2010) indicate an increase in developmental time with increase in the duration of cold storage.

The longevity of adults that emerged from both pupal stages kept at 12 and $8^{\circ} \mathrm{C}$ for a week was $17-18$ days, which is not significantly different from that recorded for the control. However, longevity markedly decreased when the pupae were stored at $4^{\circ} \mathrm{C}(13-14$ days) and decreased even further if stored for two weeks. The longevity of parasitoids that emerge from cold stored pupae depends on the energy reserves available at emergence. Ismail et al. (2010) report a direct relationship between consumption of lipids during storage and reduction in longevity of Aphidius ervi. Hence, as insects do not feed at low temperatures their survival depends on their energy reserves, which may become seriously depleted by being stored for a long period (Colinet et al., 2006). The decrease in longevity of adults that emerge from parasitoid immatures exposed to low temperature is reported for many species, such as Trichogramma species (Jalali \& Singh, 1992; Rundle et al., 2004; Nadeem et al., 2010), Telenomus busseolae (Bayram et al., 2005), Anagyrus ananatis (Pandey \& Johnson, 2005), Aphidius ervi (Ismail et al., 2010, 2013) and Diaeretiella rapae (Silva et al., 2013). In this study the longevity of E. sophia that emerged from young pupae (10 day old) after two weeks storage at a low temperature $\left(8\right.$ and $\left.4^{\circ} \mathrm{C}\right)$ was shorter than those that emerged from older pupae (12-d old), which indicates that parasitoids stored at a younger stage need more energy to complete their development and this affects their longevity.

In this study the size of the adults that emerged from late stage pupae (12 day old) were affected by the cold storage treatment, but there were no difference among the temperature treatments, whereas the adults that emerged from an early pupal stage (10 day old) were not affected by the cold storage treatment. This further indicates the response of different pupal stages to cold storage differed. Moreover, it is likely the period of exposure used in this study was too short to bring about changes in morphology similar to those recorded in their physiology.

When an immature parasitoid is exposed to low temperature, the females that survive the treatment have a greatly reduced fecundity (Jalali \& Singh, 1992; van Baaren et al., 2005; Silva et al., 2013). The duration of storage at low temperature had an adverse effect on the ability of $E$. sophia to parasitize as there was a marked decrease in percentage parasitism with increase in the time and decrease in the temperature at which they were stored. However, after a week in storage at $12^{\circ} \mathrm{C}$ the females parasitized $24.3-27.8 \%$ of the hosts. This is comparable to the quality control criterion set for E. formosa (Arthropod Mass Rearing and Quality Control Working group, IOBC, 2002). A decrease in the number of eggs laid on the first day after emergence of E. formosa that as pupae were stored for a long time at a low temperature is also reported by Lopez $\&$ Botto (2005). Ganteaume et al. (1995b) also record a reduction in daily fecundity of $E$. formosa kept at $9^{\circ} \mathrm{C}$ for 15 days. The reason for the decrease in fecundity after cold 
storage could be desiccation and starvation of the immature stages of the parasitoid during cold storage or damage to reproductive structures.

Based on the results of this study, it is concluded that $E$. sophia is adversely affected by being stored as pupae at low temperatures for long periods of time. However, percentage emergence, percentage parasitism and longevity were not adversely affected by short term storage at $12^{\circ} \mathrm{C}$. Moreover, 12 day old pupae were more tolerant of cold storage than 10 day old pupae. As the information in the literature on the effect of cold storage on E. sophia is very limited, the results of this study are important in indicating how future studies might improve the method of storing pupae and so increase the efficiency of biological control. Further studies on cold storage of this species using fluctuating temperature treatments should be considered. Hence, being able to store the parasitoids for longer with little effect on their fitness is crucial for efficient biological control.

ACKNOWLEDGEMENTS. The study was financially supported by the National Natural Science Foundation of China (31301726), National Basic Research Program of China (Grant No. 2013CB127605) and Special Fund for Agro-scientific Research in the Public Interest of China (201303019). We sincerely thank Chinese Government for the PhD scholarship awarded to the first author.

\section{REFERNCES}

Al-Tememi N.K. \& Ashfaq M. 2005: Effect of low temperature storage on the fecundity and parasitizing efficacy of Bracon hebetor (Say). - J. Agric. Res. 43: 155-160.

Arthropod Mass Rearing and Quality Control Working Group, International Organization for Biological Control 2002: IOBC Quality control guidelines for natural enemies. http://allserv.rug.ac.be/ padclerc/AMRQC/images/guidelines. pdf $(25 / 08 / 14)$.

Ayvaz A., Karasu E., Karaborklu S. \& Tunçbilek A.S. 2008: Effects of cold storage, rearing temperature, parasitoid age and irradiation on the performance of Trichogramma evanescens Westwood (Hymenoptera: Trichogrammatidae). - J. Stor. Prod. Res. 44: 232-240.

Bayram A., Ozcan H. \& Kornosor S. 2005: Effect of cold storage on the performance of Telenomus busseolae Gahan (Hymenoptera: Scelionidae), an egg parasitoid of Sesamia nonagrioides (Lefebvre) (Lepidoptera: Noctuidae). - Biol. Contr. 35: 68-77.

Bowler K. \& Terblanche J.S. 2008: Insect thermal tolerance: what is the role of ontogeny, ageing and senescence? - Biol. Rev. 83: 339-355.

Colinet H. \& Borvin G. 2011: Insect parasitoids cold storage: a comprehensive review of factors of variability and consequences. - Biol. Contr. 58: 83-95.

Colinet H. \& Hance T. 2010: Interspecific variation in the response to low temperature storage in different aphid parasitoids. - Ann. Appl. Biol. 156: 147-156.

Colinet H., Hance T. \& Vernon P. 2006: Water relations, fat reserves, survival, and longevity of a cold-exposed parasitic wasp Aphidius colemani (Hymenoptera: Aphidiinae). - Environ. Entomol. 35: 228-236.

Colinet H., Siaussat D., Bozzolan F. \& Bowler K. 2013: Rapid decline of cold tolerance at young age is associated with ex- pression of stress genes in Drosophila melanogaster. - J. Exp. Biol. 216: 253-259.

Forester L.A., Doetzer A.K. \& De Castro L.C.F. 2004: Emergence, longevity and fecundity of Trissolcus basalis and Telenomus podisi after cold storage in the pupal stage. - Pesq. Agropec. Bras. 39: 841-845.

Ganteaume A., Tabone E. \& Poinsot-Balaguer N. 1995a: Variation du potentiel biotique de l'auxiliaire parasite Encarsia formosa G. (Hym., Aphelinidae) en fonction du stockage au froid 2. Du point de vue de la fecondité journalière et de la longevité. - J. Appl. Entomol. 119: 547-551.

Ganteaume A., Tabone E. \& Poinsot-Balaguer N. 1995b: Variation du potentiel biotique de l'auxiliaire parasite Encarsia formosa G. (Hym., Aphelinidae) en fonction du stockage au froid: I. Du point de vue du taux d'emergence. - J. Appl. Entomol. 119: 419-422.

Giorgini M. \& BALDANZA F. 2004: Species status of two populations of Encarsia sophia (Girault \& Dodd) (Hymenoptera: Aphelinidae) native to different geographic areas. - Biol. Contr. 30: $25-35$.

Goolsby J.A., Ciomperlik M.A., Legaspi B.C., Legaspi J.C. \& WeNDEL L.E. 1998: Laboratory and field evaluation of exotic parasitoids of Bemisia tabaci (Gennadius) (Biotype "B") (Homoptera: Aleyrodidae) in the Lower Rio Grande Valley of Texas. - Biol. Contr. 12: 127-135.

Guo X.J., Rao Q., Zhang F., Luo C., Zhang H.Y. \& Gao X.W. 2012: Diversity and genetic differentiation of the whitefly $B e$ misia tabaci species complex in China based on mtCOI and cDNA-AFLP analysis. - J. Integr. Agric. 11: 206-214.

He Y.X., Weng Q.Y., Huang J., Liang Z.S., Ling G.J. \& Wu D.D. 2007: Insecticide resistance of Bemisia tabaci field populations. - Chin. J. Appl. Ecol. 18: 1578-1582.

Hunter M.S. \& Kelly S.E. 1998: Hyperparasitism by an exotic autoparasitoid: secondary host selection and the window of vulnerability of conspecific and native heterospecific hosts. Entomol. Exp. Appl. 89: 249-259.

Ismail M., Vernon P., Hance T. \& van BaAren J. 2010: Physiological costs of cold exposure on the parasitoid Aphidius ervi, without selection pressure and under constant or fluctuating temperatures. - BioControl 55: 729-740.

Ismail M., van Batren J., Hance T., Pierre J.-S. \& Vernon P. 2013: Stress intensity and fitness in the parasitoid Aphidius ervi (Hymenoptera: Braconidae): temperature below the development threshold combined with a fluctuating thermal regime is a must. - Ecol. Entomol. 38: 355-363.

JALALI S.K. \& SingH S.P. 1992: Biology and feeding potential of Curinus coeruleus (Mulsant) and Chrysoperla carnea (Stephens) on subabul psyllid, Heteropsylla cubana Crawford. J. Insect Sci. 5: 89-90.

LeE R.E. 2010: A primer on insect cold-tolerance. In Denlinger D.L. \& Lee R.E.Jr. (eds): Low Temperature Biology of Insects. Cambridge University Press, Cambridge, pp. 3-35.

Levie A., Vernon P. \& Hance T. 2005: Consequences of acclimation on survival and reproductive capacities of cold-stored mummies of Aphidius rhopalosiphi (Hymenoptera: Aphidiinae). - J. Econ. Entomol. 98: 704-408.

Li S.J., Xue X., Ahmed M.Z., Ren S.X., Du Y.Z., Wu J.H., CuthBERTSON A.G.S. \& QIU B.L. 2011: Host plants and natural enemies of Bemisia tabaci (Hemiptera: Aleyrodidae) in China. - Insect Sci. 18: 101-120.

Liang P., Tian Y.A., Biondi A., Desneux N. \& Gao X.W. 2012: Short-term and transgenerational effects of the neonicotinoid nitenpyram on susceptibility to insecticides in two whitefly species. - Ecotoxicology 21: 1889-1898. 
Lopez S.N. \& Botтo E. 2005: Effect of cold storage on some biological parameters of Eretmocerus corni and Encarsia formosa (Hymenoptera: Aphelinidae). - Biol. Contr. 33: 123-130.

LYSYK T.J. 2004: Effect of cold storage on development and survival of three species of parasitoids (Hymenoptera: Pteromalidae) of house fly, Musca domestia L. - Environ. Entomol. 33: 823-831.

Moiroux J., Brodeur J. \& Boivin G. 2014: Sex ratio variations with temperature in an egg parasitoid: behavioural adjustment and physiological constraint. - Anim. Behav. 91: 61-66.

Nadeem S., Ashfaq M., Hamed M. \& Ahmed S. 2010: Optimization of short and long term storage duration for Trichogramma chilonis (Ishii) (Hymenoptera: Trichogrammatidae) at low temperatures. - Pakist. J. Zool. 42: 63-67.

NAKAMA P.A. \& Foerster L.A. 2001: Efeito da alternancia de temperaturas no desenvolvimento e emergancia de Trissolcus basalis (Wollaston) e Telenomus podisi Ashmead (Hymenoptera: Scelionidae). - Neotrop. Entomol. 30: 269-275.

PAndeY R.R. \& Johnson M.W. 2005: Effects of cool storage on Anagyrus ananatis Gahan (Hymenoptera: Encyrtidae). — Biol. Contr. 35: 9-16.

Ren S.X., Zhen-Zhong W., BaO-LI Q. \& Yuan X. 2001: The pest status of Bemisia tabaci in China and non-chemical control strategies. - Entomol. Sin. 8: 279-288.

Rundle B.J., Thomson L.J. \& Hoffmann A.A. 2004: Effects of cold storage on field and laboratory performance of Trichogramma carverae (Hymenoptera: Trichogrammatidae) and the response of three Trichogramma spp. (T. carverae, T. nr. brassicae, and T. funiculatum) to cold. - J. Econ. Entomol. 97: 213-221.

Scopes N.E.A., Biggerstaff S.M. \& Goodall D.E. 1973: Cool storage of some parasites used for pest control in glasshouses. - Plant Pathol. 22: 189-193.

Silva R.J., Cividanes F.J., Pedroso E.C., Barbosa J.C., Matta D.H., Correia E.T. \& Otuka A.K. 2013: Effect of low-temperature storage on Diaeretiella rapae (McIntosh) (Hymenoptera: Braconidae). - Neotrop. Entomol. 42: 527-533.

Spínola-Filho P.R.C., Leitel G.L.D., Soares M.A., Alvarenga A.C., Daiana de Paulo P., Tuff i-Santos L.D. \& Zanuncio J.C. 2014: Effects of duration of cold storage of host eggs on per- cent parasitism and adult emergence of each of ten Trichogrammatidae (Hymenoptera) species. - Fla. Entomol. 97: 14-21.

Teng X., Wan F.H. \& ChU D. 2010: Bemisia tabaci biotype Q dominates other biotypes across China. - Fla. Entomol. 93: 363-368.

Tezze A.A. \& Botтo E.N. 2004: Effect of cold storage on the quality of Trichogramma nerudai (Hymenoptera: Trichogrammatidae). - Biol. Contr. 30: 11-16.

VAN BAaren J., OUtReman Y. \& BoIvin G. 2005: Effect of low temperature exposure on oviposition behavior and patch exploitation strategy in parasitic wasps. - Anim. Behav. 70: 153-163.

van Batren J., Boivin G. \& Outreman Y. 2006: Deleterious effects of low temperature exposure on learning expression in a parasitoid. — Int. J. Comp. Psychol. 19: 368-385.

WAN F.H., Zheng X.B. \& Guo J.Y. 2005: Biology and Management of Invasive Alien Species in Agriculture and Forestry. Science Press, Beijing, China, 820 pp.

Wan F.H., Guo J.Y. \& Zhang F. 2009: Research on Biological Invasions in China. Science Press, Beijing, $312 \mathrm{pp}$.

WANG Z., YAN H., YANG Y. \& WU Y. 2010: Biotype and insecticidal resistance status of the whitefly Bemisia tabaci from China. - Pest Manag. Sci. 66: 1360-1366.

Yang N.W., Zang L.S., Wang S., Guo J.Y., Xu H.X., Zhang F. \& WAN F.H. 2014: Biological pest management by predators and parasitoids in the greenhouse vegetables in China. - Biol. Contr. 68: 92-102.

ZANG L.S. \& LiU T.X. 2008. Intraguild interactions between Bemisia tabaci predator, Delphastus catalinae, and parasitoid, Encarsia sophia, and their impacts on Whitefly suppression. —J. Insect Sci. 8: 53.

ZANG L.S., Liu T.X., Zhang F., ShI S.S. \& Wan F.H. 2011: Effects of mating status on host feeding and parasitism in two whitefly parasitoids. - Insect Sci. 18: 78-83.

Zheng Y., Zhao J.W., He Y.X., Huang J. \& Weng Q.Y. 2012: Development of insecticide resistance and its effect factors in field population of Bemisia tabaci in Fujian Province, East China. - Chin. J. Appl. Ecol. 23: 271-277.

Received December 19, 2014; revised and accepted March 17, 2015 Prepublished online June 4, 2015 